\title{
Dissociation of binding and learning processes
}

\author{
Birte Moeller $^{1} \cdot$ Christian Frings $^{1}$
}

Published online: 27 July 2017

(C) The Psychonomic Society, Inc. 2017

\begin{abstract}
A single encounter of a stimulus together with a response can result in a short-lived association between the stimulus and the response [sometimes called an event file, see Hommel, Müsseler, Aschersleben, \& Prinz, (2001) Behavioral and Brain Sciences, 24, 910-926]. The repetition of stimulus-response pairings typically results in longer lasting learning effects indicating stimulus-response associations (e.g., Logan \& Etherton, (1994) Journal of Experimental Psychology: Learning, Memory, and Cognition, 20, 10221050]. An important question is whether or not what has been described as stimulus-response binding in action control research is actually identical with an early stage of incidental learning (e.g., binding might be seen as single-trial learning). Here, we present evidence that short-lived binding effects can be distinguished from learning of longer lasting stimulus-response associations. In two experiments, participants always responded to centrally presented target letters that were flanked by response irrelevant distractor letters. Experiment 1 varied whether distractors flanked targets on the horizontal or vertical axis. Binding effects were larger for a horizontal than for a vertical distractor-target configuration, while stimulus configuration did not influence incidental learning of longer lasting stimulus-response associations. In Experiment 2, the duration of the interval between response $n-1$ and presentation of display $n$ (500 ms vs. $2000 \mathrm{~ms}$ ) had opposing influences on binding and learning effects. Both experiments indicate that modulating factors influence stimulus-response binding and incidental learning effects in different ways. We
\end{abstract}

Birte Moeller

moellerb@uni-trier.de

1 Department of Psychology, University of Trier, Campus I, 54286 Trier, Germany conclude that distinct underlying processes should be assumed for binding and incidental learning effects.

Keywords action control $\cdot$ stimulus-response binding . incidental learning

\section{Introduction}

If we think about research on human action control, at least two different fields in psychology are essential. One focuses on individual actions: after a single response to a certain stimulus, aftereffects that are due to binding between response and stimulus features can be observed. These effects have been interpreted as indicative of the structure of the latest action plan. Then again, an obvious fact about human actions is that they are mostly carried out in an environment, full of contingencies between objects and actions. Hence, another important focus is on performance in well-known situations in which it is highly adaptive to learn stimulus-response associations to increase future performance. Both phenomenabinding and learning - seem to be important to get an understanding of how humans interact with their environment. Strikingly, however, a look at the literature reveals that it is still unclear whether the differentiation between binding effects and incidental learning is justified. In fact, the idea of feature binding stems from perception research and has been enhanced in the last decade so as to include actions too. Yet, the relationship to learning mechanism is not understood. Some researchers ignore this differentiation altogether, while others discuss the possibility that these processes are different, and finally there are some researchers suggesting that these processes are in fact the same. To understand humans' interaction with their environments, the relationship of binding and learning mechanisms in action control has to be investigated. 
Thus, the aim of the study reported in this article was to analyze whether the processes underlying binding and incidental learning effects are comparable by investigating the influence of well-known modulating variables on these effects. Before we turn to the details we briefly describe the two phenomena.

\section{Stimulus-response binding}

The use of the term "stimulus-response (SR) binding" differs widely across studies (e.g., Horner \& Henson, 2009, 2011; Rothermund, Wentura, \& De Houwer, 2005; Schnyer, Dobbins, Nicholls, Davis, Verfaellie, \& Schacter, 2007). Here, we focus on effects found in paradigms that include a first distinct event, during which integration of stimuli and responses can take place, and a second event that can be influenced by this integration and is typically presented in direct sequence to the integration event (e.g., Hommel, 1998; Frings, Rothermund, \& Wentura, 2007; Mayr \& Buchner, 2006).

Theoretically, effects in these studies have been assumed to be due to temporary associations between stimulus and response features that can result from a single stimulus-response pairing (Henson, Eckstein, Waszak, Frings, \& Horner, 2014). According to one interpretation, these temporary associations result from integration of action plans (e.g., Stoet \& Hommel, 1999), which can be accounted for by the Theory of Event Coding (TEC, Hommel et al., 2001). In order to carry out a response, features of the response and stimulus features are integrated in an action plan (often labelled 'event file' in this research area) that consists of a number of binary temporary associations (Giesen \& Rothermund, 2014a; Hommel, 1998, 2004; Moeller, Frings, \& Pfister, 2016) that have been called bindings. After an action is carried out, bindings start to disintegrate. During the time it takes to fully disintegrate them, residual bindings may influence further actions: if any of the integrated features is repeated, other bound features or the entire event file can be reactivated. Reactivation of an earlier response then leads to increased performance if the reactivated and the current response are compatible, but to impaired performance if they are incompatible. We will refer to this result pattern as stimulus-response binding effects.

With regard to the possibility that binding might rely on the same processes as incidental learning, it is important to note that even response irrelevant distractor stimuli can become part of an action plan and retrieve integrated responses later on-an effect that has been termed distractor-response binding (Frings et al., 2007; Rothermund et al., 2005).

\section{Incidental SR learning}

If binding cannot be differentiated from learning, but is indeed an early step in at least some form of learning, incidental SR learning is a likely candidate. Repeatedly responding to a certain stimulus in a certain way leads to incidental learning of associations between stimuli and responses (e.g., Fitts \& Deininger, 1954; Fitts \& Seeger, 1953; recently shown by e.g., Grant \& Logan, 1993; Kiesel, Wendt, \& Peters, 2007; Schmidt, Crump, Cheesman, \& Besner, 2007; Wendt \& Kiesel, 2008). This is also the case if participants have no intention to learn associations regarding ignored features. Investigation of such incidental learning is possible with tasks that require participants to complete a speeded choice reaction to a target stimulus while ignoring other stimuli that appear contingently with certain targets or certain responses (e.g., Logan \& Etherton, 1994; Miller, 1987; Schmidt \& De Houwer, 2012). If an ignored stimulus is repeatedly presented together with a certain response, participants are faster and more accurate to respond to contingent than to noncontingent pairings. We use the term incidental learning to describe this sort of picking up SR associations.

One possibility to account for incidental learning is the Instance Theory of Automatization (ITA, Logan, 1988, 1990, see Schmidt, De Houwer, \& Besner, 2010). The ITA assumes a transition from performance based on a general algorithm, to performance based on memory retrieval, with increasing experience with a stimulus. More specifically, each encounter with a stimulus that we respond to is integrated in an instance that is stored in long term memory. Instances are assumed to include relevant items, their interpretations, the current goals while responding, and the response (Boronat \& Logan, 1997). The same act of attention that enables integration of new instances also triggers retrieval of past instances from memory, including their actions. Retrieval of past actions then competes with the initiation of the current response, and whichever process finishes first determines performance. With an increasing number of retrieved instances, it becomes more likely that one of the retrieval processes is completed before the newly initiated response is carried out. If the retrieval process wins this race regularly, the behavior is understood to be automatic (Logan, 1988). In addition, it has been proposed that the most recently encountered instances are also the most accessible (Grant \& Logan, 1993; Schmidt et al., 2010). Recent stimulus-response combinations then have a particularly large potential to be retrieved and are most likely to influence performance.

Several studies report evidence for incidental learning between non-target features, or stimuli and responses after repeated pairings. For example, Miller (1987) introduced contingencies between otherwise response-irrelevant distractor letters and responses in an Eriksen Flanker task and found faster responding if the SR combination in a test block was compatible to the distractor-response contingency in the training block. The same is also true for separate distractor words 
(Logan \& Etherton, 1994, Logan, Taylor, \& Etherton, 1996, 1999). Apparently, human participants learn associations between their own responses and ignored stimuli within a single experiment, often within no more than a few dozen responses.

\section{Identical processes in SR-binding and incidental SR-learning?}

In most studies investigating binding or learning effects, the authors do not clearly demarcate one process from the other. Instead, many authors hint that binding might be an early process in learning (e.g., Dutzi \& Hommel, 2009; Frings \& Rothermund, 2011; Giesen, Frings, \& Rothermund, 2012; Giesen \& Rothermund, 2014a, b; Hommel, 1998; Moeller \& Frings, 2014a, b; Waszak \& Pholulamdeth, 2009; see also Wolfensteller \& Ruge, 2011), or they treat binding entirely as learning, using both terms interchangeably (e.g., Henson, 2003; Horner \& Henson, 2009, 2011, 2012; Schnyer, et al., 2007; Schnyer, Dobbins, Nicholls, Schacter, \& Verfaellie, 2006; Waszak, Hommel, \& Allport, 2003). Yet, it is essential to decide whether or not binding and incidental learning effects rely on the same processes. If binding effects are caused by learning mechanisms, it would be straightforward to use the same label for identical processes and start to address binding effects as evidence for incidental learning. Consequently, past studies regarding binding could be reinterpreted as single-trial learning. By contrast, increasing evidence that the phenomena are really differentiable would call for a much more distinct interpretation of mechanisms that cause binding effects on the one hand and learning processes on the other hand. In fact, both learning and action planning theories might benefit if influences of both mechanisms could be discerned in a given result pattern.

In the light of such substantial theoretical implications, it is high time to directly address the question whether the effect that has been investigated in binding paradigms is indeed caused by a learning process or whether it can be differentiated from incidental learning. The present study was conducted to take a first step towards resolving this issue.

\section{Evidence for binding $=$ learning}

On the one hand, it is possible that the effects measured in binding paradigms are indeed due to instance retrieval from memory. First, in many paradigms, it is rather difficult to empirically differentiate between effects assumed by TEC and ITA. Instances and event files are supposed to contain very much the same things (e.g., relevant items, their interpretations, and current goals; Boronat \& Logan, 1997; Hommel, 2004), and the retrieval process assumed for event files has been shown to be identical to that of instance retrieval (Frings \& Moeller, 2012). Moreover, the predictions for effects of instance retrieval on the following response are identical to the typically observed binding effects. For example, performance in responding to a stimulus is better if the same response was already given to the stimulus on an earlier occasion. Such a result might be due to residual activations of action plan associations (i.e., binding), but it might also be due to the retrieval of an instance from longterm memory.

Thus, it is not surprising that numerous studies forgo differentiation. For example, repetition priming effects can be explained by an association of stimulus and response features that occurs at the first encounter and influences responding on the next encounter. Notably, only priming after a single encounter, and most likely within a limited time frame after this encounter, might be purely due to residual action-plan bindings. Yet, it is common in the literature to ignore any possible difference between priming resulting from binding and priming resulting from incidental learning of stimulus-response associations: More priming is usually associated with an increasing number of prior presentations of a stimulus (e.g., Dennis \& Schmidt, 2003; Dobbins, Schnyer, Verfaellie, \& Schacter, 2004; Gotts, Chow, \& Martin, 2012; Schnyer et al., 2007; Schnyer et al., 2006; Wiggs \& Martin, 1998), and priming effects due to a single SR presentation, and due to repeated presentations, have been treated as the same sort of binding effect (Denkinger \& Koutstaal, 2009; Frings, Moeller, \& Horner 2015). Even authors who explicitly point out that SR-bindings can be formed in a single SR pairing and do not need to be learned gradually, do not always clearly differentiate between binding and learning (Henson et al., 2014).

There is also theoretical reason to doubt the separability of the binding and learning processes. Just consider the progression of incidental contingency learning. At the first encounter of a stimulus-response combination, it is impossible to decide whether it is the beginning of a contingency or just a random single combination. Obviously, some mechanism is necessary to select likely candidates for - and keep track of - contingencies. Associations within action plans could theoretically fulfill this function. In line with this, event files have been proposed to play a central role for the first stage of action-effect learning (Dutzi \& Hommel, 2009) in the two-stage model of goal-directed action (Elsner \& Hommel, 2001, 2004; Hommel 1997, 1998; Hommel \& Elsner, 2009; Wolfensteller \& Ruge, 2011). Possibly, bindings in action plans that are formed in the course of human behavior, and that already include relevant and salient features of the situation, are also used to detect contingencies. Here, the only necessary additional assumption would be that traces of bindings can last for longer than a couple of seconds. If this is the case, however, it becomes impossible to distinguish bindings within an event file (see Hommel et al., 2001) from associations within an instance (see Logan, 1988). This becomes apparent if we look at the structural similarities of TEC and ITA. The most obvious 
proposed difference between event files and instances has been their assumed life spans. While bindings resulting from event files are supposed to be disintegrated shortly after responding, instances are assumed to be directly stored in long-term memory. Yet, neither TEC nor ITA specify boundary conditions for the duration of event files or instances. On the contrary, no upper bound has been reported for event files, and they have been shown to last for at least $6 \mathrm{~s}$ (Herwig \& Waszak, 2012), while it has been suggested that recent instances are more accessible in automatization learning than instances that were integrated further in the past (Grant \& Logan, 1993; Schmidt et al., 2010). Considering such longlived event-files, together with large retrieval potential of recent instances, adds to the plausibility that bindings are indeed identical to associations within instances. Therefore, the more straightforward approach might be to understand effects that have been measured in binding paradigms as effects of instance retrieval.

\section{Evidence for binding $\neq$ learning}

Turning to the possibility that binding and learning can be dissociated, first note that authors who hint that binding might be relevant for a longer learning process, implicitly assume that binding can be differentiated from learning (e.g., Giesen \& Rothermund, 2014a; Frings \& Rothermund, 2011; Hommel, 1998; Moeller \& Frings, 2014a). More importantly, evidence in related fields seems to indicate differences between short-term aftereffects of stimulus encounters and long-term learning effects. Specifically, Wagner, Maril, and Schacter (2000) present a theoretical account together with evidence that priming in fact hinders incidental learning. The authors assume that a decrease in neural activation at repeated stimulus presentation (neural priming effect) results in sparse re-encoding variability. In turn, learning is hindered as compared to more variable re-encoding. Indeed the authors found less explicit memory for words presented twice with a short time lag (a few minutes) between first and second presentation than for words presented twice with a long time lag (1 day). These findings are in line with those regarding explicit memory: repetitions of an item after a short lag (which is associated with more priming) produced lower levels of subsequent explicit memory than did repetition of the item after a long lag (Greene, 1992; Melton, 1967; Ebbinghaus, 1885/1964). Most importantly for the present study, Kirsner and Speelman (1996) analyzed power function speed up as predicted by the ITA for repetition priming and skill acquisition, and found that repetition priming does not conform to this principle, while skill acquisition does. They conclude that repetition priming (which can be interpreted as an effect of SR binding) and skill learning involve different processes (but see Gupta \& Cohen, 2002; Poldrack, Selco, Field, \& Cohen, 1999).
As mentioned above, the question whether or not binding and incidental learning involve identical processes has been largely ignored in the past. Therefore, only very little direct evidence exists regarding this question. Yet in the few studies available that come close to the topic, there seems to be a tendency to interpret the findings as indicating differentiation of binding and learning.

Analyzing bindings in familiar objects, Colzato and colleagues found no modulation of binding effects by familiarity of feature combinations. However, a comparison of their different experiments suggested larger partial repetition costs for natural objects than for arbitrary feature combinations (Colzato, Raffone, \& Hommel, 2006, see also Hommel \& Colzato, 2009). More specifically, Hommel and Colzato (2009) report significantly larger feature binding effects for familiar than for arbitrary objects. The authors propose a differentiation between ad hoc bindings of new-and conjunction detection of familiar - stimuli (see also VanRullen, 2009). Only familiar objects have an entry in long-term memory that influences binding effects regarding visual stimulus features and does not extend to visuomotor integration. Binding of new stimuli, on the other hand, is entirely dependent on the current attentional set, includes integration of response features, and cannot be influenced by long-term memory entries.

In line with this, Moeller and Frings (2017) also assume differentiable processes. Yet, unlike Hommel and Colzato (2009), they present evidence for at least one direction of influence between long-term associations and short-term bindings. The authors report binding effects for the pronunciation of a word and a visually presented and incompatible non-word, but no binding effects for word pronunciation and a visually presented incompatible word. That is, highly automated stimulus response associations seem to be able to hinder binding of the stimulus with an incompatible response.

Importantly, the studies cited can only give a first indication of the way a long-term association might (not) influence binding effects. They do not provide insight into a possible overlap of the processes that cause feature binding effects on the one hand, and enable incidental learning on the other. Findings with regard to the integration of actions with effects might provide a first hint here.

Action-effect associations have been proposed to be learned faster in an intentional mode (i.e., the participant intends to produce a certain effect by responding) than in a stimulus based mode (i.e., the participant is prompted by a stimulus to give a certain response, which then also has some unintended effect; e.g., Herwig, Prinz, \& Waszak, 2007; Herwig \& Waszak, 2009; for a discussion of association mode in the acquisition versus test phase, see Pfister, Kiesel, \& Hoffmann, 2011). On the other hand, short-term binding between responses and effects is also possible if participants respond in a stimulus based mode (e.g., Janczyk, Heinemann, \& Pfister, 2012). Herwig and Waszak 
(2012) analyzed binding between responses and effects and learning of response-effect associations, and found differences between learning and binding effects: influences of action mode (intention based vs. stimulus based) were only observed for learning, but not for short-term binding. Although interpretation of the results is ambiguous, this evidence can be taken as a first indication that incidental learning and binding need to be differentiated, at least with regard to action-effect associations.

\section{The present study}

Taken together, the great majority of past literature has ignored the question of whether binding effects and learning rely on identical or separable processes. Strikingly, the apparent reason for such disregard differs fundamentally between researchers. While some authors seem to be convinced that binding effects are an indication of learning (e.g., Denkinger \& Koutstaal, 2009), others naturally treat the process underlying binding effects as one that can be dissociated from learning (e.g., Frings, et al., 2007; Rothermund, et al., 2005). Some formal theories discuss binding effects as part of a learning process (Dutzi \& Hommel, 2009, Elsner \& Hommel, 2001; Wolfensteller \& Ruge, 2011), but others differentiate between short-term priming - and long-term learning - effects of stimulus encounters (Wagner et al., 2000). Finally, only a little empirical evidence exists regarding this question and, even based on the few studies that come close to attempting a differentiation, a clear interpretation seems to be impossible. Hence, regarding implicit assumptions, theoretical accounts, and also past evidence, there is a substantial disagreement between the suggestion that binding effects are caused by a learning process and the idea that the processes of short-term binding and incidental learning can be differentiated. With the present study, we address this issue.

If the processes underlying binding and incidental learning are indeed identical, we would expect more learning in setups that boost binding effects as compared to setups with only small binding effects. In two experiments, we systematically varied factors that are known to modulate binding effects and that are also likely to influence learning. In turn, we assessed whether these manipulations influenced incidental learning and binding in a similar way, as would be expected if binding effects result from a learning process. In contrast, if binding and incidental learning rely on separate processes, those factors modulating binding effects are unlikely to modulate learning in a similar way. We will specify the expected effects on incidental learning for this case below.

To anticipate the results, variations in stimulus grouping modulated binding, but not learning effects (Experiment 1), while the same pacing manipulation even had contrary effects on learning and binding (Experiment 2).

\section{Experiment 1}

To act in a complex environment, it is necessary to subdivide an entire scene into meaningful parts. Gestalt psychologists have proposed a number of principles like similarity, proximity, and continuity, which are used to organize visual scenes (Koffka, 1935; Köhler, 1947; see Palmer 1999). Notably, binding effects and learning effects have been shown to be influenced by Gestalt grouping principles. First, it is well known that associations between stimuli are learned more readily if the stimuli are grouped than if they are presented in a non-grouped fashion (Baker, Olson, \& Behrmann, 2004; Conci, Müller, \& von Mühlenen, 2013; Fiser, Scholl, \& Aslin, 2007; Newport \& Aslin, 2004). For example, associations between stimulus pairs within a stimulus triplet were learned only if both stimuli of the contingently presented pair had the same color, but not if the two stimuli differed in color (Glicksohn \& Cohen, 2011). In addition, distractor-response binding effects are typically larger if distractor and target stimuli are presented in a grouped setup, than if they are presented in a non-grouped setup (Frings \& Rothermund, 2011; Moeller, Rothermund, \& Frings, 2012). For example, if participants responded to target letters that were flanked by distractor letters, distractor-response binding effects were stronger if the stimulus configuration was horizontal (resembling a word) than if the configuration was vertical (Frings \& Rothermund, 2011).

Yet, note that the studies cited measured slightly different influences of stimulus-grouping. Grouping of stimuli led to more stimulus-stimulus association learning. That is, associations are learned more readily between grouped than between non-grouped stimuli. By contrast, grouping of target and distractor stimuli led to more short-term association between distractor stimulus and the response to the target. That is, binding to a third non-grouped component of the situation (i.e., the response) was modulated by stimulus grouping. To our knowledge, such modulation has never been shown for incidental association learning. Yet, if binding effects and incidental learning are caused by identical processes, the same modulation should also enhance incidental distractor-response association learning directly. Accordingly, Experiment 1 was designed to test whether modulating stimulus grouping influenced incidental distractor-response learning in a way corresponding to binding modulations. During the entire experiment, a participant saw distractor- and target letters either presented in a horizontal line, giving the impression of a word, or in a vertical column (see Frings \& Rothermund, 2011). Since learned associations between a distractor stimulus and a response have been shown to influence binding (Moeller \& Frings, 2014b; Moeller \& Frings, 2017), binding effects were measured 
independently of learning blocks. The first part of the experiment was a conceptual replication of Miller's (1987) study, and was composed of one training phase, containing contingencies between distractor stimuli and responses, and one test phase, presenting the former distractors as targets, either compatibly or incompatibly mapped to the responses, associated during training. Note that distractor stimuli in the training phase indicated the correct response in $90 \%$ of the trials, and were therefore not truly response irrelevant as distractor stimuli were in the test phase. The second part of the experiment was a conceptual replication of Experiments 2a and $2 \mathrm{~b}$ of Frings and Rothermund (2011). Participants responded in a prime-probe sequence that required a response to each prime and each probe display, and varied response repetition between prime and probe orthogonally to distractor repetition. Importantly, no contingencies between distractor-stimuli and responses were included in this second part of the experiment.

Based on the findings in the previous studies, we expected to find a compatibility effect in the test block of the first experimental phase (i.e., faster and/or more accurate responding to stimuli that were mapped to the same response as associated in the training block than to stimuli mapped to the incompatible response), indicating incidental learning of distractor-response associations during training. Focusing on incidental learning, we make no assumptions as to whether or not participants might become aware of the contingencies. For the second part of the experiment, we expected a larger facilitation effect due to distractor repetition (as compared to distractor change) between prime and probe if the response had to be repeated than if the response had to be changed from prime to probe (i.e., an interaction of response relation and distractor relation), indicating binding between distractor and response. Note that it is essential to test binding via this interaction, as any separate comparison of two of the four cells resulting from varying response and distractor relation can be distorted by additional main effects influencing reaction times (RTs) (e.g., response repetition or distractor inhibition effects). Importantly, this binding effect was expected to be larger if target and distractors were presented in a grouped (i.e., horizontal) stimulus configuration than if they were presented in a non-grouped (i.e., vertical) configuration (see Fig. 1a). Of particular interest was whether stimulus configuration also had an effect on incidental distractor-response association learning. Based on past research, we can assume that the grouping of target and distractor influences learning of distractor-target associations. Effects of such learning on the results were precluded by exchanging target stimuli between learning and test phase. Markedly, an influence of target-distractor grouping on incidental distractor-response association learning cannot be predicted. That is, unless binding is caused by a learning process, we would expect the compatibility effect not to be modulated by stimulus configuration (see Fig. 1c).

\section{Method}

\section{Participants}

Seventy students ( 55 female) from the University of Trier took part in the experiment. Two participants failed to report their age. The median age of the remaining sample was 22 years with a range from 19 years to 39 years. Three additional participants were excluded from the analysis. One seemed to be intoxicated, one was sick during testing, and a third had an extremely high error rate in the test phase of the experiment. All participants took part in exchange for partial course credit or monetary compensation.

\section{Design}

The factor stimulus configuration (horizontal vs. vertical arrangement of targets and distractors) was varied between participants. Compatibility of stimulus-response mapping (compatible vs. incompatible) in the block testing learning effects was varied within participants. The design of the block, testing binding effects, comprised two within-subjects factors, namely response relation (response repetition vs. response change), and distractor relation (repetition vs. change).

\section{Materials}

The experiment was conducted using the E-prime 2.0 software. Instructions and stimuli were shown in white on black background on a standard CRT screen. Consonants were used as stimuli. All letters subtended a horizontal and vertical visual angle of $0.8^{\circ}$. Viewing distance was approximately $60 \mathrm{~cm}$. Participants responded by pressing one of two keys on the computer keyboard.

\section{Procedure}

Participants were tested individually in soundproof chambers. Instructions were given on the screen and summarized by the experimenter. Participants were instructed to place their left index finger on the D key and their right index finger on the $\mathrm{K}$ key of a standard computer keyboard. They were told that they would always see one target letter, flanked by two identical distractor letters. Their task was always to categorize the target letter by pressing a key with the corresponding finger. One group of participants always saw the three letters in a horizontal row, and the other group always saw them in a vertical 
a)

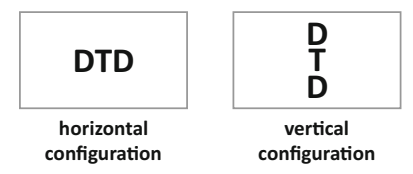

b)

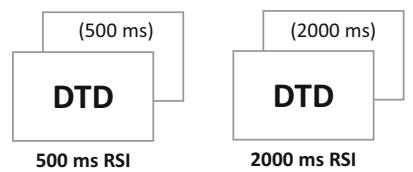

c)

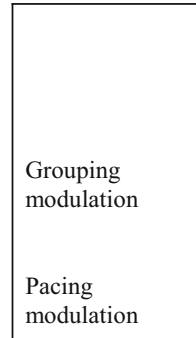

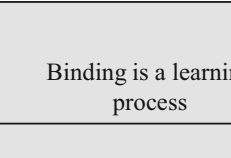

horizontal > vertical

$500 \mathrm{~ms}$ RSI > 2000 ms RSI
Learning effects Binding differs from
learning

horizontal $=$ vertical

500 ms RSI $<2000$ ms RSI

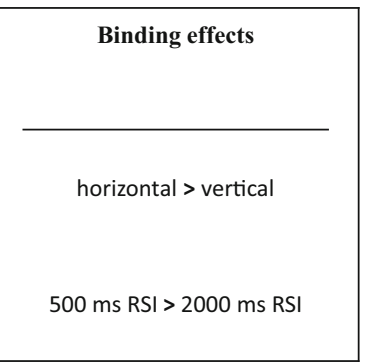

grouping and pacing influences on binding and learning effects. Different modulations of learning effects are expected dependent on the assumptions that binding can be differentiated from learning effects (middle column) or not (left column) column (Fig. 1a). Each participant worked through three blocks of trials.

The first block (200 trials) served as a learning phase, the second block ( 80 trials) was used to measure any learning that took place during the first block, and the third block (160 trials) was used to measure binding effects with the exact same stimulus configuration as used in the first two blocks, but utilizing different letters as target and distractor stimuli. For each subject, the 20 consonants were randomly assigned to the different roles in the experiment. Four letters served as targets in the first block (two were assigned to each response). Four different letters were presented as distractors in the first block. Two of these distractors appeared in $90 \%$ of the trials that required a left-hand response, and in $10 \%$ of the trials that required a right-hand response. Complementary, the other two distractors appeared in $90 \%$ of the trials that required a right-hand response and in $10 \%$ of the trials that required a left-hand response. That is, overall each distractor was presented in the same percentage of trials in the learning block.

In the second block (the block testing learning effects), these same letters were then used as targets. Of the two distractors previously associated with the left-hand response, one was now mapped to the left and the other to the right response in the test block, resulting in compatible and incompatible stimulus-response mappings. The two distractors that had been associated with the right-hand response were mapped to the two responses in the same way. Four new letters were used as distractor stimuli in the test block. None of the stimuli in the test block were presented contingently with a response or with another stimulus.

The sequence within individual trials was identical in the first two blocks. The target and distractor stimuli appeared and remained in the middle of the screen until participants responded. Then a feedback display was presented for $1000 \mathrm{~ms}$ informing the participant, whether the last response was correct or not. Finally, the screen went blank for $1500 \mathrm{~ms}$ inter-trial interval.

In the third block, testing distractor-response binding effects, four new letters were used as targets (two were assigned to each response) and four new letters were used as distractor stimuli.

For measuring distractor-response binding effects, a prime-probe sequence was utilized. Thus, an individual trial consisted of the following events. The prime target and distractors appeared in the middle of the screen and remained there until participants responded. In case of an incorrect response, an error message was presented for $1000 \mathrm{~ms}$, reminding the participant to respond as fast as possible, but without making errors. Then the screen went blank for $500 \mathrm{~ms}$. Probe target and distractors were then presented in the middle of the display until participants responded. As before, an error message was presented for $1000 \mathrm{~ms}$ in case of an incorrect response. Finally, a blank screen was presented for $1500 \mathrm{~ms}$ inter-trial interval. Response relation and distractor relation were varied orthogonally between prime and probe of the binding block. In response repetition (RR) trials, the same response was required on the prime and the probe. In response change (RC) trials, different responses had to be given to the prime and probe target. Similarly, in distractor repetition (DR) trials, the same letter was presented as the distractor on prime and probe displays, while in distractor change (DC) trials, different letters were presented as prime 
and probe distractors. Hence, four different conditions were realized in the binding block: response repetition with distractor repetition (RRDR), response repetition with distractor change (RRDC), response change with distractor repetition (RCDR), and response change with distractor change (RCDC).

The same order of blocks was used for all participants to maximize the probability for the distractor-response contingencies to be learned (in the first block). Since no contingencies were present in the block measuring binding effects, we assumed that experiencing this block first might decrease the probability for picking up contingencies in the same task, later on. Before the first block started, participants practiced the task for 20 trials and before the third block started, a practice of eight trials was included. These practice trials were a subsample of the trials in the following blocks.

\section{Results}

For the analysis of RTs, we considered only those trials with correct responses (to both the prime and the probe in case of the binding block). Error rates were $5.1 \%$ in the learning block and $5.2 \%$ in the test block; in the binding block, probe error rate was $4.1 \%$ and prime error rate was $3.9 \%$. RTs that were more than 1.5 interquartile ranges above the third quartile of the RT distribution of the sample (Tukey, 1977), and those that were shorter than $200 \mathrm{~ms}$ were excluded from the analysis. Due to these constraints, $10.8 \%$ of the trials in the learning block, $12.8 \%$ of the test block, and $13.0 \%$ of the binding block were discarded. For mean RTs and error rates in the conditions of the three blocks see Table 1 .

\section{Learning block}

In a 2 (stimulus configuration: horizontal vs. vertical) $\times 2$ (distractor-response compatibility: compatible vs. incompatible) MANOVA on RTs with Pillai's trace as the criterion, the main effect of compatibility was significant, $F(1,68)=27.45$, $P<.001, \eta_{\mathrm{p}}{ }^{2}=.29$, indicating faster responses, if the response indicated by the target was also compatible to the distractors $(M=612 \mathrm{~ms}, \mathrm{SD}=74 \mathrm{~ms})$ than if the response indicated by the target was incompatible to the distractors $(M=634 \mathrm{~ms}, \mathrm{SD}$ $=83 \mathrm{~ms})$. Neither the main effect of stimulus configuration, $F(1,68)<1, P=.889, \eta_{\mathrm{p}}^{2}<.01$, nor the interaction of compatibility with stimulus configuration was significant, $F(1,68)<1, P=.360, \eta_{\mathrm{p}}{ }^{2}=.01$. In the same analysis on error rates we found numerically the same pattern. However, the main effect of compatibility did not reach significance, $F(1,68)=3.13, P=.081, \eta_{\mathrm{p}}{ }^{2}=.04$. The main effect of stimulus configuration, $F(1,68)<1, P=.405, \eta_{\mathrm{p}}{ }^{2}=.01$, and the interaction were not significant, $F(1,68)<1, P=.493$, $\eta_{\mathrm{p}}^{2}<.01$.
Table 1 Mean response times (in ms) and mean error rates (in parentheses) in Experiment 1 and Experiment 2

\begin{tabular}{llllll}
\hline & \multicolumn{2}{c}{ Experiment 1 Grouping } & & \multicolumn{2}{c}{ Experiment 2 Pacing } \\
\cline { 5 - 6 } & Horizontal & Vertical & & RSI $500 \mathrm{~ms}$ & RSI $2000 \mathrm{~ms}$ \\
\hline Learning & & & & \\
Incompatible & $635(6.7)$ & $634(5.4)$ & & $544(6.0)$ & $595(6.0)$ \\
Compatible & $609(5.2)$ & $615(4.7)$ & $533(5.4)$ & $585(4.6)$ \\
Test & & & & \\
Incompatible & $626(5.4)$ & $644(5.6)$ & $534(4.8)$ & $615(5.2)$ \\
Compatible & $613(4.6)$ & $627(5.1)$ & $531(6.6)$ & $596(4.9)$ \\
Binding & & & & \\
RRDR & $497(4.1)$ & $523(3.4)$ & $472(4.1)$ & $553(4.1)$ \\
RRDC & $526(2.8)$ & $537(3.3)$ & $490(5.1)$ & $555(4.0)$ \\
RCDR & $550(6.2)$ & $573(6.0)$ & $529(6.2)$ & $588(4.2)$ \\
RCDC & $552(3.9)$ & $573(4.8)$ & $523(4.7)$ & $585(4.1)$ \\
\hline
\end{tabular}

For the learning phase, compatible refers to the $90 \%$ of trials in that a distractor stimulus appeared together with its to-be-associated response; incompatible refers to the $10 \%$ of trials in that a distractor appeared together with the not to-be-associated response. For the test phase, compatible and incompatible refer to the (former distractor, now target) stimulus response mapping compared to the associations learned during the training phase. For the binding condition, mean probe response times are shown. $R R$ Response repetition, $R C$ response change, $D R$ distractor repetition, $D C$ distractor change

\section{Test block}

In a 2 (stimulus configuration: horizontal vs. vertical) $\times 2$ (stimulus-response compatibility: compatible vs. incompatible) MANOVA on RTs with Pillai's trace as the criterion, the main effect of compatibility was significant, $F(1,68)=9.26, P$ $=.003, \eta_{\mathrm{p}}{ }^{2}=.12$, indicating faster responses to target stimuli that were mapped to the response to which they were previously associated $(M=620 \mathrm{~ms}, \mathrm{SD}=90 \mathrm{~ms})$ than those for which the mapping was incompatible to the previously learned association $(M=635 \mathrm{~ms}, \mathrm{SD}=94 \mathrm{~ms})$. Neither the main effect of stimulus configuration, $F(1,68)<1, P=.462$, $\eta_{\mathrm{p}}{ }^{2}<.01$, nor the interaction of compatibility with stimulus configuration, $F(1,68)<1, P=.657, \eta_{\mathrm{p}}{ }^{2}<.01$, was significant (see Fig. 2, upper part, left side). In the same analysis on error rates none of the effects were significant, all $F \mathrm{~s}<1, P \mathrm{~s}>.35$, $\eta_{\mathrm{p}}^{2}<.02$.

\section{Binding block}

In a 2 (stimulus configuration: horizontal vs. vertical) $\times 2$ (response relation: repetition vs. change) $\times 2$ (distractor relation: repetition vs. change) MANOVA on probe RTs with Pillai's trace as the criterion, the main effects of response relation, $F(1,68)=214.78, P<.001, \eta_{\mathrm{p}}{ }^{2}=.76$, and distractor relation, $F(1,68)=29.53, P<.001, \eta_{\mathrm{p}}{ }^{2}=.30$, were significant. Responses were faster for response repetition $(M=521 \mathrm{~ms}$, 


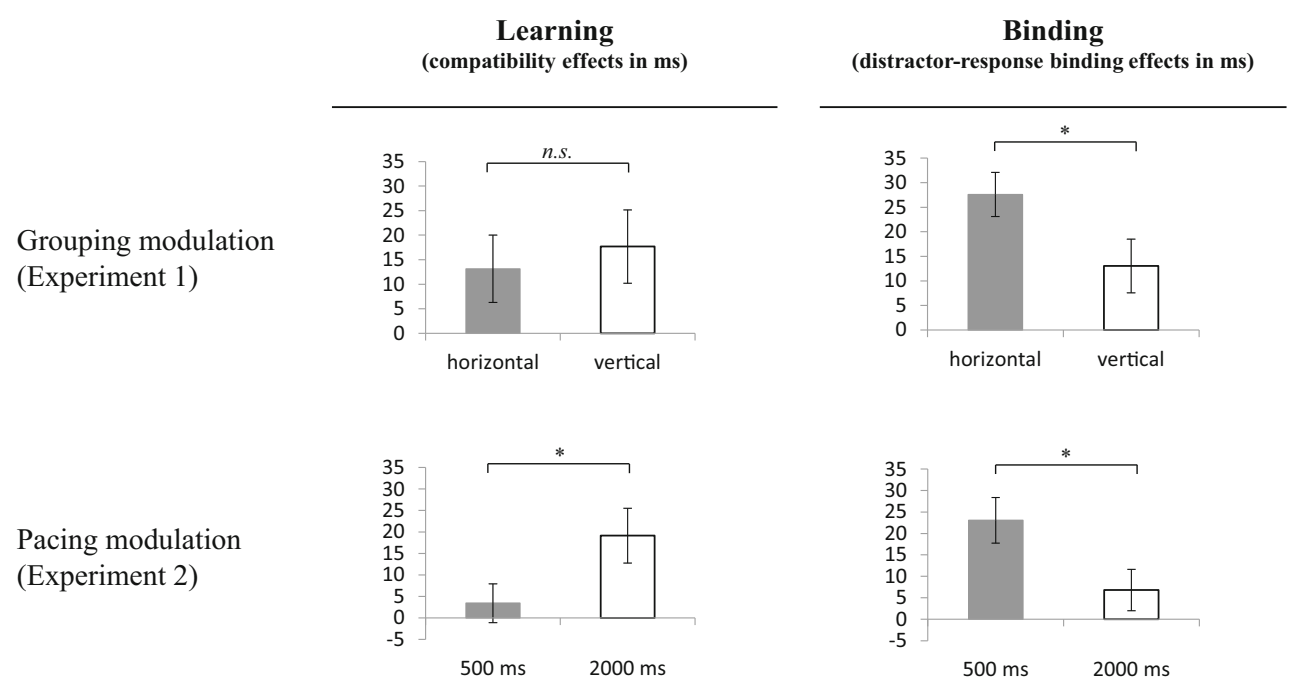

Fig. 2 Binding and learning effects in $\mathrm{ms}$ as a function of grouping and pacing modulations. Learning effects are calculated as the difference between stimulus-response-incompatible and -compatible trials in the test block. Distractor-response binding effects are calculated as the

difference between distractor repetition effects in response repetition and response change trials in the binding block (repetitions and changes from trial $n-1$ to trial $n$ ). Error bars Standard error of the mean

$\mathrm{SD}=64 \mathrm{~ms})$ than for response change trials $(M=562 \mathrm{~ms}, S D$ $=68 \mathrm{~ms})$, and responses were faster if the distractor repeated from prime to probe $(M=535 \mathrm{~ms}, \mathrm{SD}=67 \mathrm{~ms})$ than if the distractor changed $(M=546 \mathrm{~ms}, \mathrm{SD}=64 \mathrm{~ms})$. Importantly, the interaction of response relation and distractor relation was also significant, $F(1,68)=32.88, P<.001, \eta_{\mathrm{p}}{ }^{2}=.33$, indicating a general effect of distractor-response binding (the advantage due to distractor repetition as compared to distractor change was larger in response repetition than in response change trials; see Table 1). Most importantly, this effect was further modulated by stimulus configuration, $F(1,68)=4.23, P=.044, \eta_{\mathrm{p}}{ }^{2}=.06$ (see Fig. 2 , upper part, right side). Separate analyses indicated a larger effect of distractor-response binding, if target and distractors were presented in a horizontal configuration, $F(1,34)=37.49, P<$ $.001, \eta_{\mathrm{p}}{ }^{2}=.52$, than if they were arranged vertically, $F(1,34)$ $=5.68, P=.023, \eta_{\mathrm{p}}{ }^{2}=.14$. For the sake of completeness, the interaction of distractor relation and stimulus configuration, $F(1,68)=4.01, P=.049, \eta_{\mathrm{p}}{ }^{2}=.06$ was also significant, while the response relation $\times$ stimulus configuration interaction, $F(1,68)<1, P>.5, \eta_{\mathrm{p}}{ }^{2}<.01$, was not. In the same analysis on error rates, only the main effects of response relation, $F(1,68)=17.27, P<.001, \eta_{\mathrm{p}}{ }^{2}=.20$, and distractor relation, $F(1,68)=8.08, P=.006, \eta_{\mathrm{p}}{ }^{2}=.11$, were significant. All other $F_{\mathrm{s}}<2, P \mathrm{~s}>.16, \eta_{\mathrm{p}}^{2}<.03$.

\section{Discussion}

Experiment 1 clearly replicated past studies regarding binding and learning effects (Frings \& Rothermund, 2011; Miller, 1987). On the one hand, additional flanking distractor- stimuli were integrated with responses given to a target stimulus, leading to distractor-response binding effects. On the other hand, contingently presenting specific distractor stimuli together with specific responses led to incidental distractorresponse association learning. Moreover, our results also indicate that the same stimulus grouping modulation that influenced binding effects had no effect on incidental learning. Although binding effects were clearly modulated by stimulus configuration, the same horizontal and vertical setups led to no difference in learning effects. This is a first indication that grouping principles regarding target and distractor stimuli are likely not used to infer contingencies between distractors and responses. Apparently, for a modulation of incidental learning, elements need to be directly affected by grouping principles (e.g., Baker, et al., 2004; Glicksohn \& Cohen, 2011). This is different for the processes underlying stimulus-response binding effects. Here, stimulus grouping seems to modulate the structure of response association within an event file.

The findings of Experiment 1 suggest that incidental learning was not directly influenced by the process that resulted in binding effects. To be able to distinguish the processes even more clearly, in Experiment 2 we took a closer look at another aspect that may have a larger potential to differentiate effects of separate binding and learning processes.

\section{Experiment 2}

Stoet and Hommel (1999) found that action plans are disintegrated very soon after action execution, and that 
individual elements of the action plan (i.e., feature codes) can remain activated for up to $1 \mathrm{~s}$. In fact, past research investigating binding typically used very short intervals around $500 \mathrm{~ms}$ between integration and retrieval (Colzato et al., 2006; Giesen \& Rothermund, 2014a; Moeller \& Frings, 2015; Waszak, Hommel, \& Allport, 2004). Moreover, in line with an assumption of fast action plan disintegration, binding effects that were present with $500 \mathrm{~ms}$ response-stimulus intervals (RSI) were smaller or disappeared if the RSI was extended to $2000 \mathrm{~ms}$ (Frings, 2011; Moeller, Pfister, Kunde, \& Frings, 2016).

In contrast, if we take a closer look at studies implementing contingencies to analyze incidental learning, it becomes clear that learning is possible with a rather slow pacing (Logan \& Etherton, 1994; Miller, 1987; Schmidt \& Besner, 2008; Schmidt et al., 2007, Schmidt, et al., 2010). At least $1000 \mathrm{~ms}$ RSI were used, when contingencies between additional stimuli and responses were learned (e.g., Logan \& Etherton, 1994; Miller, 1987). Moreover, repeated presentation of a stimulus led to more learning with long than with short intervals between the individual presentations (Wagner et al., 2000). In general, presentation of separate instances spaced widely in time typically leads to more learning than closely spaced presentation (Cepeda, Pashler, Vul, Wixeted, \& Rohrer, 2006; Greene, 1989, 1990, 1992; Kahana \& Howard, 2005; Melton, 1967, 1970). Thus, with a timing manipulation, we might be able to reach a dissociation of learning and binding processes. If binding effects are indeed larger for short than for long RSIs while learning effects are larger for long rather than for short RSIs (see Fig. 1c), it can be ruled out that binding is caused by a process of incidental learning.

Experiment 2 was very similar to Experiment 1. However, only horizontal stimulus configurations were presented, and the crucial variation was the pacing of response and subsequent display presentation. The trial sequence in all blocks of the experiment was identical, including stimulus presentation until response followed by a fixed interval before the next stimulus display was presented. The critical manipulation was the duration of the RSI. It either lasted for $500 \mathrm{~ms}$ or for $2000 \mathrm{~ms}$ throughout the experiment (i.e., both in learning blocks and also in binding blocks). In addition, in Experiment 1 we kept the order of learning and binding blocks constant to maximize the probability for learning to take place. To control for sequence effects that might account for any findings with such a design, in Experiment 2, the order of learning and binding blocks was counterbalanced.

\section{Method}

\section{Participants}

Seventy-one students (59 female) from the University of Trier took part in the experiment. Their median age was 22 years with a range from 18 to 29 years. Two additional participants were excluded from the analyses because they were much older than the otherwise very homogenous sample (more than three interquartile ranges above the third quartile of the sample, Tukey, 1977). All participants took part in exchange for partial course credit or monetary compensation.

\section{Design}

The factors block order (learning first vs. binding first) and pacing (500 ms RSI vs. $2000 \mathrm{~ms}$ RSI) were varied between participants. Compatibility of stimulus-response mapping (compatible vs. incompatible) in the block, testing learning effects, was varied within participants. The relevant withinsubjects factors of the block, testing binding effects, were response relation (repetition vs. change from response $n-1$ to response $n$ ), and distractor relation (repetition vs. change form response $n-1$ to response $n$ ).

\section{Materials and procedure}

Materials and procedure of the learning and test blocks was identical to that of Experiment 1, with the following exceptions. All participants saw target and distractor letters in a horizontal configuration. However, the inter-trial interval (of all blocks) differed between participants. For half of the participants, $500 \mathrm{~ms}$ elapsed between response $n-1$ and presentation of display $n$, and for the other half, $2000 \mathrm{~ms}$ passed (see Fig. 1b). As in Experiment 1, only letters that were not presented in the learning blocks were used as stimuli in the binding block. Four targets were mapped to the left and right response (two to each side) and two different letters were used as distractors. Targets and distractors were randomly assigned in each display. The same sequence of events was realized as in the learning and test block: target and distractors were presented until participants responded, and then an inter-trial interval of $500 \mathrm{~ms}$ (or $2000 \mathrm{~ms}$, respectively) elapsed before the next stimulus presentation. Each participant experienced the same inter-trial interval $(500 \mathrm{~ms}$ or $2000 \mathrm{~ms})$ in all three blocks. Approximately half of the participants $(n=36)$ experienced the learning blocks before the binding block and the other half experienced the binding block first.

\section{Results}

For the analysis of RTs, we considered only those trials with correct responses in the learning and the test block, and only correct responses that followed a correct response in the binding block. Error rates were $5.1 \%$ in the learning block, $5.4 \%$ in the test block, and $4.2 \%$ in the binding block. Response times that were more than 1.5 interquartile ranges above the third quartile of the RT distribution of the participant (Tukey, 1977), and those that were shorter than $200 \mathrm{~ms}$ were excluded from the analysis. Due to these constraints, $10.6 \%$ trials of the 
learning block, $12.9 \%$ of the test block, and $13.4 \%$ of the binding block were discarded. For mean RTs and error rates in the conditions of the three blocks see Table 1. The factor block order (learning first vs. binding first) did not significantly modulate any of the relevant main or interaction effects reported below. For the sake of clarity, we therefore dropped this factor from the reported analyses.

\section{Learning block}

In a 2 (pacing: RSI $500 \mathrm{~ms}$ vs. RSI $2000 \mathrm{~ms}$ ) $\times 2$ (distractorresponse compatibility: compatible vs. incompatible) MANOVA on RTs with Pillai's trace as the criterion, both main effects were significant [pacing: $F(1,69)=7.15, P=$ $.009, \eta_{\mathrm{p}}{ }^{2}=.09$; compatibility: $F(1,69)=11.39, P=.001, \eta_{\mathrm{p}}{ }^{2}$ $=.14]$. Responses were faster with $500 \mathrm{~ms}$ RSI $(M=535 \mathrm{~ms}$, $\mathrm{SD}=68 \mathrm{~ms})$ than with $2000 \mathrm{~ms} \mathrm{RSI}(M=586 \mathrm{~ms}, \mathrm{SD}=90$ $\mathrm{ms}$ ), and participants responded faster, if the response indicated by the target was also compatible to the distractors $(M=$ $559 \mathrm{~ms}, \mathrm{SD}=83 \mathrm{~ms}$ ) than if the response indicated by the target was incompatible to the distractors $(M=570 \mathrm{~ms}, \mathrm{SD}=$ $86 \mathrm{~ms})$. The interaction of compatibility with pacing was not significant, $F(1,69)<1, P=.882, \eta_{\mathrm{p}}{ }^{2}<.01$. In the same analysis on error rates, none of the effects was significant, $F_{\mathrm{s}}<2, p \mathrm{~s}>.14, \eta_{\mathrm{p}}^{2}<.04$.

\section{Test block}

In a 2 (pacing: RSI $500 \mathrm{~ms}$ vs. RSI $2000 \mathrm{~ms}$ ) $\times 2$ (stimulusresponse compatibility: compatible vs. incompatible) MANOVA on RTs with Pillai's trace as the criterion, both main effects were significant [pacing: $F(1,69)=15.93, P<$ $.001, \eta_{\mathrm{p}}{ }^{2}=.19$; compatibility: $F(1,69)=8.28, P=.005, \eta_{\mathrm{p}}{ }^{2}=$ .11]. Responses were faster with $500 \mathrm{~ms}$ RSI $(M=533 \mathrm{~ms}$, SD $=58 \mathrm{~ms})$ than with $2000 \mathrm{~ms}$ RSI $(M=605 \mathrm{~ms}, \mathrm{SD}=91 \mathrm{~ms})$, and participants responded faster, if the SR mapping was compatible $(M=564 \mathrm{~ms}, \mathrm{SD}=81 \mathrm{~ms})$ than if the mapping was incompatible $(M=575 \mathrm{~ms}, \mathrm{SD}=91 \mathrm{~ms})$. Importantly, the interaction of compatibility with pacing was also significant, $F(1,69)=4.01, P=.049, \eta_{\mathrm{p}}{ }^{2}=.06$ (see Fig. 2, lower part, left side). Pairwise comparisons showed that the compatibility effect, indicating incidental learning, was only significant for slow pacing (RSI $2000 \mathrm{~ms}$ ), $t(35)=3.00, P=.005, d=$ 0.50 , but not for fast pacing (RSI $500 \mathrm{~ms}$ ), $t(34)=0.76, P=$ $.451, d=0.13$. In the same analyses on error rates none of the effects was significant, all $F_{\mathrm{s}}<1.7, P \mathrm{~s}>.2, \eta_{\mathrm{p}}{ }^{2}<.03$.

\section{Binding block}

In a 2 (pacing: RSI $500 \mathrm{~ms}$ vs. RSI $2000 \mathrm{~ms}) \times 2$ (response relation from $n-1$ to $n$ : repetition vs. change) $\times 2$ (distractor

\footnotetext{
${ }^{0}$ We thank an anonymous reviewer for this suggestion.
}

relation from n-1 to n: repetition vs. change) MANOVA on RTs with Pillai's trace as the criterion, the main effects of pacing, $F(1,69)=17.74, P<.001, \eta_{\mathrm{p}}{ }^{2}=.21$, and response relation, $F(1,69)=126.44, P<.001, \eta_{\mathrm{p}}{ }^{2}=.65$, were significant. Responses were faster with RSI of $500 \mathrm{~ms},(M=502 \mathrm{~ms}$, $\mathrm{SD}=56 \mathrm{~ms})$, than with $2000 \mathrm{~ms} \mathrm{RSI}(M=570 \mathrm{~ms}, \mathrm{SD}=76$ $\mathrm{ms})$, and faster for response repetition $(M=518 \mathrm{~ms}, \mathrm{SD}=75$ $\mathrm{ms}$ ) than for response change trials $(M=557 \mathrm{~ms}, \mathrm{SD}=77 \mathrm{~ms})$. The interaction of response relation and distractor relation was also significant, $F(1,69)=15.11, P<.001, \eta_{\mathrm{p}}{ }^{2}=.18$, indicating a general effect of distractor-response binding (The advantage due to distractor repetition as compared to distractor change was larger in response repetition than in response change trials; see Table 1). Most importantly, this effect was further modulated by pacing, $F(1,69)=6.29, p=$ $.015, \eta_{\mathrm{p}}{ }^{2}=.08$ (see Fig. 2, lower part, right side). Separate analyses indicated a significant effect of distractor-response binding only for fast pacing (RSI $500 \mathrm{~ms}$ ), $F(1,35)=19.78$, $P<.001, \eta_{\mathrm{p}}{ }^{2}=.36$, but not for slow pacing (RSI $2000 \mathrm{~ms}$ ), $F(1,36)=1.30, P=.262, \eta_{\mathrm{p}}{ }^{2}=.04$. For the sake of completeness, the interaction of distractor relation $\times$ pacing, $F(1,69)=$ 4.76, $P=.032, \eta_{\mathrm{p}}{ }^{2}=.07$, reached significance, as well, while the main effect of distractor relation, $F(1,69)=2.34, P=.130$, $\eta_{\mathrm{p}}{ }^{2}=.03$, and the interaction of response relation $\times$ pacing, $F(1,69)=3.42, P=.069, \eta_{\mathrm{p}}{ }^{2}=.05$, were not significant. In the same analysis on error rates, the pattern was identical. The interaction of response relation and distractor relation, $F(1,69)=5.28, P=.025, \eta_{\mathrm{p}}{ }^{2}=.07$, was significant, indicating a general binding effect. As in the RTs, binding was further modulated by pacing, $F(1,69)=5.17, P=.026, \eta_{\mathrm{p}}{ }^{2}=.07$. Separate analyses again indicated that the distractor-response binding effect was only significant for fast, $F(1,34)=9.71, p=$ $.004, \eta_{\mathrm{p}}{ }^{2}=.22$, but not for slow, $F(1,35)<1, P=.987, \eta_{\mathrm{p}}{ }^{2}<$ .01 , pacing. None of the other effects reached significance, $F \mathrm{~s}$ $<2, P \mathrm{~s}>.17, \eta_{\mathrm{p}}{ }^{2}<.03$.

\section{Discussion}

Distractor-response binding effects were found only with $500 \mathrm{~ms}$ RSI, but not with $2000 \mathrm{~ms}$ RSI. In contrast, incidental distractor-response association learning emerged only with $2000 \mathrm{~ms}$ RSI, but not with $500 \mathrm{~ms}$ RSI. That is, we replicated past findings that binding effects can only be found with a short interval between distractor-response integration and subsequent retrieval of the event file, which can then influence responding (Frings, 2011). Our findings also add to the evidence that learning is more pronounced with widely than with closely spaced presentation of individual learning instances (Cepeda et al., 2006). Moreover, the formation of long-term memory entries was prevented under circumstances that enable the measurement of binding effects.

Of course, it is highly unlikely that binding of stimuli and responses generally prevents incidental learning. Instead, it is 
safe to assume that each action in the slow pacing block was enabled by an action plan that included bindings - just like the actions in the fast pacing block. However, sufficient time between responding and the next event seems to be a prerequisite for the system to pick up contingencies. This might indicate that the learning mechanism, responsible for monitoring or storing contingencies, needs some time, and is in line with a number of past suggestions and findings. Greene $(1989,1990)$ proposed two processes that may account for better learning in widely spaced presentation as compared to closely spaced presentation. On the one hand, if individual learning instances are presented close together repeated items seem more familiar, and therefore less effort is put into learning these. On the other hand, individual episodes of widely spaced learning instances are more distinct (for example, they are more likely to occur in different contexts). Consequently, they are easier to retrieve. Since participants in the present experiment had no learning instruction, strategies required for the first proposed mechanism are improbable. Therefore, we suppose that the distinctness and easier retrieval of the individual learning instances is more likely to have influenced our results.

Another possibility is that a relatively long RSI is necessary for the detection of distractor-response contingency which might occur (partly) after responding and after SRprocessing has been completed. Consequently, short RSIs would have led to interference with the contingency detect process from stimulus presentation in trial $n+1$ while longer RSIs caused less interference. ${ }^{1}$

Note that distractor-response association learning seems to be evident in both learning phases. That is, the difference between learning and binding effects in the present study might be due to impairment in the manifestation of learning (rather than due to learning not taking place). Yet, an unambiguous interpretation of the results of the learning phase is impossible for several reasons. First, the mean response times in the incompatible conditions relied on only 20 trials per subject (as compared to 180 compatible trials contributing to the other mean). More importantly, since the task differed between learning and test phases, we have to assume that the compatibility effects in the learning and test blocks were likely caused by different mechanisms. In particular, effects in the training phase of the $500 \mathrm{~ms}$ RSI condition may have been due to binding effects: since $90 \%$ of the trials were compatible, it was much more likely that any given trial $n$ was preceded by a compatible trial. If the distractor was then repeated, response retrieval due to binding led to facilitation if trial $n$ was compatible, and to impairment of performance if trial $n$ was incompatible. Therefore, we cannot discern for the training phases whether learning or binding led to differences between compatible and incompatible trials.

Altogether, Experiment 2 clearly indicates that binding effects and incidental learning are differently modulated by the same pacing conditions. Based on these results, we propose that binding and learning should be regarded as different phenomena that rely on separate processes.

\section{General discussion}

In the present study, we systematically analyzed whether two different factors had a similar influence on binding effects and incidental learning, as hypothesized by the assumption that binding is caused by a learning process, or whether influences differed, indicating disparity of the underlying processes. Our results clearly support the latter assumption. Experiment 1 replicates the finding that binding effects are stronger for horizontal than for vertical stimulus configurations. However, the same modulation of stimulus configuration had no impact on incidental learning of distractor-response associations. Ignored stimuli were associated with responses to a similar extent, independently of stimulus configuration. Moreover, Experiment 2 provided evidence that presentation rate (RSI) had opposite influences on binding and learning effects. Binding effects were only present with $500 \mathrm{~ms}$, but not with $2000 \mathrm{~ms}$ RSI, while incidental learning was only possible with $2000 \mathrm{~ms}$, but not with $500 \mathrm{~ms}$ RSI. Together, these results draw a clear picture: SR binding is not identical to incidental learning.

\section{Theoretical implications and future directions}

Most importantly, the present results indicate different underlying processes for two phenomena (binding and incidental learning) that were almost impossible to distinguish in the past. Regarding the current result pattern, bindings may be understood as functional entities of action plans (see Hommel, 2004; Stoet \& Hommel, 1999). For flexible behavior, it is central that these bindings are easily and sometimes quickly disintegrated. It is also central that they function similarly well in familiar and in unfamiliar situations. Integration of longer term associations on the other hand, has to depend on the identification of contingencies between the associated stimuli and responses, which calls for storage of either a sort of contingency counter or the SR association itself on a longer term basis. Various processes have been suggested to lead to long-term memory representations that may be retrieved on a later occasion. Among those are repetition (Logan 1988) or rehearsal (Waugh \& Norman, 1965) of instances or items, relevance (Herwig \& Waszak, 2012), distinctness (Greene, 1989, 1990), or emotional significance (McGaugh, 2000) of the event, and the level of information encoding (Craik \& Lockhart, 1972). Identifying the exact mechanisms for incidental long-term memory encoding is beyond the scope of the present study. Nevertheless, our results indicate one mechanism that cannot account for incidental learning; namely 
short-term integration of stimulus and response codes within an action plan.

Our findings have important implications for the interpretation of past studies that did not explicitly distinguish between binding and learning. In particular, one arising question is which of the reported effects were due to incidental learning processes and which were due to binding. The experimental design of a study might provide a first hint for the underlying processes of the measured effects. If stimulus features and responses were orthogonally varied within an experimental session, incidental learning is unlikely to have contributed to the result pattern, and it seems safe to assume underlying binding processes. Presence of SR contingencies, on the other hand, are a good indicator that incidental learning will have influenced the results. Hence, some past studies might need a re-interpretation. For example, Frings et al. (2015) report binding effects, although their introduction of contingencies between fixation mark identity and response suggest that their effects were likely due to incidental learning and not binding processes.

Another relevant indicator for the processes underlying a given result pattern may be timing between integration and retrieval. In this sense, effects reported by Horner and Henson (2009, 2011; see also Hsu \& Waszak, 2012; Moutsopoulou, Yang, Desantis, \& Waszak, 2015) are more likely caused by learning than by binding processes. The authors found response retrieval due to stimulus repetition (after a single first encounter) after retention intervals of 10-15 min and several dozen responses to different stimuli. It is highly unlikely that residual associations of action plans can survive such long times as well as repeated exchanges of working memory contents. Learning on the other hand is conceivable, considering that pictures of objects were used as stimulus material and their deep encoding was ensured by the task to decide whether the depicted object is larger or smaller than a shoebox in real life.

Finally, modulating factors of an effect can point towards one set of underlying processes or the other. If associations between additional task irrelevant stimuli and responses vary with the current stimulus grouping, the effect can be assumed to be driven by binding processes. Likewise, if stimulus grouping does not modulate such an effect, binding processes are unlikely to have influenced the results. More importantly, even if stimulus grouping is not varied, the specific stimulus setup of an experiment allows an estimation of which processes were more likely involved. For example, in a typical Eriksen Flanker paradigm, presenting target and distractor stimuli in a horizontal line, binding processes are likely to contribute to the result pattern. In contrast, in vertical arrays of target and distractor stimuli (e.g., Logan \& Etherton, 1994), contributions by binding processes are unlikely, and effects are more realistically due to learning processes.
The notion that SR-binding effects are not caused by incidental learning has substantial implications also for future research. First, both in learning and in binding studies researchers are well advised to clearly differentiate the terminology for short-term bindings and long-term learning. Seeing that these rely on different processes, referring to one implies a different set of characteristics that can be assumed for the process than referring to the other (e.g., the way the process might be influenced by conditions like stimulus grouping or pacing).

This above suggestion also touches on another important issue that follows from the present findings. It will be necessary to practically differentiate binding and incidental learning effects also in more ambiguous situations. In other words, the boundary conditions of short-term binding on the one hand and longer-term learning on the other, need to be identified. For example, it may be more difficult to ascribe effects that range over longer time spans than binding effects in the current study (e.g., Herwig \& Waszak, 2012; Hommel \& Colzato, 2004; Horner \& Henson, 2009, 2011) to one process or the other. It is plausible that the particular circumstances of residual bindings can modulate their life span. For instance, bindings between target stimuli and responses are stronger and have a longer duration than distractor-response bindings (e.g., Frings, 2011; Herwig \& Waszak, 2012; Ihrke, Behrendt, Schrobsdorff, Herrmann, \& Hasselhorn, 2011; Moeller et al., 2016). Closer investigation of factors modulating the duration of bindings seems to be a promising starting point. In addition, searching for other qualities besides duration that can differentiate between binding and learning is similarly important. One approach could be a careful comparison between the structures of action plans and incidentally learned associations.

Seeing that bindings can be differentiated from incidental learning effects, a challenging question is whether, under what circumstances, and to what extent the mechanisms underlying the two phenomena may influence each other. First evidence seems to suggest that binding effects vary with advancing learning (Moeller \& Frings, 2014b; Moeller \& Frings, 2017). Furthermore, other literature indicates that priming (i.e., the presence of a short term integration) hinders learning of a longer-term association (e.g., Wagner et al., 2000). It is conceivable that both directions of influence lead to a more complex interaction of processes responsible for incidental learning and binding.

For action control in general, this means that we identified two distinct sets of processes that influence human behavior in everyday life. The first set can enable flexible behavior, and the second utilizes contingencies in our environment to facilitate fast and correct actions in familiar situations. In the past, underlying processes of both phenomena (incidental learning and binding) have either been investigated in separate fields of psychology or assumed to be identical. With regard to the 
present findings, we propose that a new line of investigation should consider both aspects of action control together with possible superposition or interaction of their effects.

\section{Conclusion}

Based on the present results, we conclude that processes underlying binding effects need to be treated as dissociable from learning. Putting this suggestion into practice has important indications for the interpretation of past research, and raises several issues that need to be addressed in the future. As a starting point, binding and learning mechanisms should be addressed in terms of their likely underlying functions. A reasonable approach may be to interpret binding effects as residual activations of recent action plans reflecting the flexibility of human actions, and not as the first manifestation of learning future SR associations.

Acknowledgements The research reported in this article was supported by a grant of the Deutsche Forschungsgemeinschaft to Birte Moeller (MO 2839/2-1).

\section{References}

Baker, C. I., Olson, C. R., \& Behrmann, M. (2004). Role of attention and perceptual grouping in visual statistical learning. Psychological Science, $15,460-466$.

Boronat, C. B., \& Logan, G. D. (1997). The role of attention in automatization: does attention operate at encoding, or retrieval, or both? Memory \& Cognition, 25, 36- 46.

Cepeda, N. J., Pashler, H., Vul, E., Wixted, J. T., \& Rohrer, D. (2006). Distributed practice in verbal recall tasks: a review and quantitative synthesis. Psychological Bulletin, 132, 354-380.

Colzato, L. S., Raffone, A., \& Hommel, B. (2006). What do we learn from binding features? evidence for multilevel feature integration. Journal of Experimental Psychology: Human Perception and Performance, 32, 705-716.

Conci, M., Müller, H. J., \& von Mühlenen, A. (2013). Object-based implicit learning in visual search: perceptual segmentation constrains contextual cueing. Journal of Vision, 13, 15.

Craik, F. I., \& Lockhart, R. S. (1972). Levels of processing: a framework for memory research. Journal of Verbal Learning and Verbal Behavior, 11(6), 671-684.

Denkinger, B., \& Koutstaal, W. (2009). Perceive-decide-act, perceivedecide-act: how abstract is repetition-related decision learning? Journal of Experimental Psychology: Learning, Memory, and Cognition, 35, 742-756.

Dennis, I., \& Schmidt, K. (2003). Associative processes in repetition priming. Journal of Experimental Psychology: Learning, Memory, and Cognition, 29, 532-538.

Dobbins, I. G., Schnyer, D. M., Verfaellie, M., \& Schacter, D. L. (2004). Cortical activity reductions during repetition priming can result from rapid response learning. Nature, 428, 316-319.

Dutzi, I. B., \& Hommel, B. (2009). The microgenesis of action-effect binding. Psychological Research, 73, 425-435.

Ebbinghaus, H. (1885/1964). Memory: A contribution to experimental psychology. New York: Dover.
Elsner, B., \& Hommel, B. (2001). Effect anticipation and action control. Journal of Experimental Psychology: Human Perception and Performance, 27, 229-240.

Elsner, B., \& Hommel, B. (2004). Contiguity and contingency in the acquisition of action effects. Psychological Research, 68, 138-154.

Fiser, J., Scholl, B. J., \& Aslin, R. N. (2007). Perceived object trajectories during occlusion constrain visual statistical learning. Psychonomic Bulletin \& Review, 14, 173-178.

Fitts, P. M., \& Deininger, R. L. (1954). SR compatibility: correspondence among paired elements within stimulus and response codes. Journal of Experimental Psychology, 48(6), 483-492.

Fitts, P. M., \& Seeger, C. M. (1953). SR compatibility: spatial characteristics of stimulus and response codes. Journal of Experimental Psychology, 46(3), 199-210.

Frings, C. (2011). On the decay of distractor-response episodes. Experimental Psychology, 58, 125-131.

Frings, C., \& Moeller, B. (2012). The horserace between distractors and targets: retrieval-based probe responding depends on distractortarget asynchrony. Journal of Cognitive Psychology, 24, 582-590.

Frings, C., Moeller, B., \& Horner, A. (2015). On the durability of bindings between responses and response-irrelevant stimuli. Acta Psychologica, 161, 73-78.

Frings, C., \& Rothermund, K. (2011). To be or not to be...included in an event file: integration and retrieval of distractors in stimulus-response episodes is influenced by perceptual grouping. Journal of Experimental Psychology: Learning, Memory, \& Cognition, 37, $1209-1227$.

Frings, C., Rothermund, K., \& Wentura, D. (2007). Distractor repetitions retrieve previous responses to targets. The Quarterly Journal of Experimental Psychology, 60, 1367-1377.

Giesen, C., Frings, C., \& Rothermund, K. (2012). Investigating the interplay of top-down and bottom-up control of behavior: differences in the strength of inhibition do not affect distractor-response bindings. Memory \& Cognition, 40, 373-387.

Giesen, C., \& Rothermund, K. (2014a). Distractor repetitions retrieve previous responses and previous targets. Experimental dissociations of distractor-response and distractor-target bindings. Journal of Experimental Psychology: Learning, Memory, and Cognition, 40, 645-659.

Giesen, C., \& Rothermund, K. (2014b). You better stop! Binding "stop" tags to irrelevant stimulus features. Quarterly Journal of Experimental Psychology, 67, 809-832.

Glicksohn, A., \& Cohen, A. (2011). The role of Gestalt grouping principles in visual statistical learning. Attention, Perception, \& Psychophysics, 73, 708-713.

Gotts, S. J., Chow, C. C., \& Martin, A. (2012). Repetition priming and repetition suppression: multiple mechanisms in need of testing. Cognitive Neuroscience, 3, 250-259.

Grant, S. C., \& Logan, G. D. (1993). The loss of repetition priming and automaticity over time as a function of degree of initial learning. Memory \& Cognition, 21, 611-618.

Greene, R. L. (1989). Spacing effects in memory: evidence for a twoprocess account. Journal of Experimental Psychology: Learning, Memory, and Cognition, 15, 371-377.

Greene, R. L. (1990). Spacing effects on implicit memory tests. Journal of Experimental Psychology: Learning, Memory, and Cognition, 16, 1004-1011.

Greene, R. L. (1992). Repetition paradigms. In R. L. Greene (Ed.), Human memory: paradigms and paradoxes (pp. 132-152). Hillsdale, NJ: Erlbaum.

Gupta, P., \& Cohen, N. J. (2002). Theoretical and computational analysis of skill learning, repetition priming, and procedural memory. Psychological Review, 109, 401-448.

Henson, R. N. (2003). Neuroimaging studies of priming. Progress in Neurobiology, 70, 53-81. 
Henson, R. N., Eckstein, D., Waszak, F., Frings, C., \& Horner, A. J. (2014). Stimulus-response bindings in priming. Trends in Cognitive Sciences, 18, 376-384.

Herwig, A., Prinz, W., \& Waszak, F. (2007). Two modes of sensorimotor integration in intention-based and stimulus-based actions. The Quarterly Journal of Experimental Psychology, 60(11), 1540-1554.

Herwig, A., \& Waszak, F. (2009). Intention and attention in ideomotor learning. The Quarterly Journal of Experimental Psychology, 62(2), 219-227.

Herwig, A., \& Waszak, F. (2012). Action-effect bindings and ideomotor learning in intention- and stimulus-based actions. Frontiers in Psychology, 3, 444.

Hommel, B. (1997). Toward an action-concept model of stimulus-response compatibility. Advances in Psychology, 118, 281-320.

Hommel, B. (1998). Event files: evidence for automatic integration of stimulus-response episodes. Visual Cognition, 5, 183-216.

Hommel, B. (2004). Event files: feature binding in and across perception and action. Trends in Cognitive Sciences, 8, 494-500.

Hommel, B., \& Colzato, L. (2004). Visual attention and the temporal dynamics of feature integration. Visual Cognition, 11(4), 483-521.

Hommel, B., \& Colzato, L. S. (2009). When an object is more than a binding of its features: Evidence for two mechanisms of visual feature integration. Visual Cognition, 17, 120-140.

Hommel, B., \& Elsner, B. (2009). Acquisition, representation, and control of action. In E. Morsella, J. A. Bargh, \& P. M. Gollwitzer (Eds.), Oxford handbook of human action (pp. 371-398). New York: Oxford University Press.

Hommel, B., Müsseler, J., Aschersleben, G., \& Prinz, W. (2001). Codes and their vicissitudes. Behavioral and Brain Sciences, 24, 910-926.

Horner, A. J., \& Henson, R. N. (2009). Bindings between stimuli and multiple response codes dominate long-lag repetition priming in speeded classification tasks. Journal of Experimental Psychology: Learning, Memory, and Cognition, 35, 757-779.

Horner, A. J., \& Henson, R. (2011). Stimulus-response bindings code both abstract and specific representations of stimuli: evidence from a classification priming design that reverses multiple levels of response representation. Memory \& Cognition, 39, 1457-1471.

Horner, A. J., \& Henson, R. N. (2012). Incongruent abstract stimulusresponse bindings result in response interference: FMRI and EEG evidence from visual object classification priming. Journal of Cognitive Neuroscience, 24, 760-773.

Hsu, Y. F., \& Waszak, F. (2012). Stimulus-classification traces are dominant in response learning. International Journal of Psychophysiology, 86, 262-268.

Ihrke, M., Behrendt, J., Schrobsdorff, H., Herrmann, J., \& Hasselhorn, M. (2011). Response-retrieval and negative priming - encoding- and retrieval-specific effects. Experimental Psychology, 58, 154-161.

Janczyk, M., Heinemann, A., \& Pfister, R. (2012). Instant attraction: immediate action-effect bindings occur for both, stimulus-and goal-driven actions. Frontiers in Psychology, 3, 446.

Kahana, M. J., \& Howard, M. W. (2005). Spacing and lag effects in free recall of pure lists. Psychonomic Bulletin \& Review, 12, 159-164.

Kiesel, A., Wendt, M., \& Peters, A. (2007). Task switching: on the origin of response congruency effects. Psychological Research, 71(2), $117-125$.

Kirsner, K., \& Speelman, C. (1996). Skill acquisition and repetition priming: one principle, many processes? Journal of Experimental Psychology: Learning, Memory, and Cognition, 22, 563-575.

Koffka, K. (1935). Principles of Gestalt psychology. New York: Harcourt Brace.

Köhler, W. (1947). Gestalt psychology: an introduction to new concepts in modern psychology. New York: Liveright.

Logan, G. D. (1988). Toward an instance theory of automatization. Psychological Review, 95, 492-527.

Logan, G. D. (1990). Repetition priming and automaticity: common underlying mechanisms? Cognitive Psychology, 22, 1-35.
Logan, G. D., \& Etherton, J. L. (1994). What is learned during automatization? The role of attention in constructing an instance. Journal of Experimental Psychology: Learning, Memory, and Cognition, 20, 1022-1050.

Logan, G. D., Taylor, S. E., \& Etherton, J. L. (1996). Attention in the acquisition and expression of automaticity. Journal of Experimental Psychology: Learning, Memory and Cognition, 22, 620-638.

Logan, G. D., Taylor, S. E., \& Etherton, J. L. (1999). Attention and automaticity: toward a theoretical integration. Psychological Research, 62, 165-181.

Mayr, S., \& Buchner, A. (2006). Evidence for episodic retrieval of inadequate prime responses in auditory negative priming. Journal of Experimental Psychology: Human Perception and Performance, 32, 932-943.

McGaugh, J. L. (2000). Memory - a century of consolidation. Science, 287(5451), 248-251.

Melton, A. W. (1967). Repetition and retrieval from memory. Science, $158,532-532$.

Melton, A. W. (1970). The situation with respect to the spacing of repetitions and memory. Journal of Verbal Learning and Verbal Behavior, 9, 596-606.

Miller, J. (1987). Priming is not necessary for selective-attention failures: semantic effects of unattended, unprimed letters. Perception \& Psychophysics, 41, 419-434.

Moeller, B., \& Frings, C. (2014a). Attention meets binding: only attended distractors are used for the retrieval of event files. Attention, Perception, \& Psychophysics, 76, 959-978.

Moeller, B., \& Frings, C. (2014b). Long term response-stimulus associations can influence distractor-response bindings. Advances in Cognitive Psychology, 10, 68-80.

Moeller, B., \& Frings, C. (2015). Distractor-response bindings in dual task scenarios. Visual Cognition, 23, 516-531.

Moeller, B., \& Frings, C. (2017). Overlearned responses hinder SR binding. Journal of Experimental Psychology: Human Perception and Performance, 43, 1-5.

Moeller, B., Frings, C., \& Pfister, R. (2016). The structure of distractorresponse bindings: conditions for configural and elemental integration. Journal of Experimental Psychology: Human Perception and Performance, 42, 464-479.

Moeller, B., Pfister, R., Kunde, W., \& Frings, C. (2016). A common mechanism behind distractor-response and response-effect binding? Attention, Perception, \& Psychophysics, 78, 1074-1086.

Moeller, B., Rothermund, K., \& Frings, C. (2012). Integrating the irrelevant sound: grouping modulates the integration of irrelevant auditory stimuli into event files. Experimental Psychology, 59, 258-264.

Moutsopoulou, K., Yang, Q., Desantis, A., \& Waszak, F. (2015). Stimulus-classification and stimulus-action associations: effects of repetition learning and durability. The Quarterly Journal of Experimental Psychology, 68, 1744-1757.

Newport, E. L., \& Aslin, R. N. (2004). Learning at a distance I. Statistical learning of non-adjacent dependencies. Cognitive Psychology, 48, $127-162$.

Palmer, S. (1999). Vision science: photons to phenomenology. Cambridge, MA: MIT Press.

Pfister, R., Kiesel, A., \& Hoffmann, J. (2011). Learning at any rate: action-effect learning for stimulus-based actions. Psychological Research, 75(1), 61-65.

Poldrack, R. A., Selco, S. L., Field, J. E., \& Cohen, N. J. (1999). The relationship between skill learning and repetition priming: experimental and computational analyses. Journal of Experimental Psychology: Learning, Memory, and Cognition, 25, 208-235.

Rothermund, K., Wentura, D., \& De Houwer, J. (2005). Retrieval of incidental stimulus-response associations as a source of negative priming. Journal of Experimental Psychology: Learning, Memory, and Cognition, 31, 482-495. 
Schmidt, J. R., Crump, M. J. C., Cheesman, J., \& Besner, D. (2007). Contingency learning without awareness: evidence for implicit control. Consciousness \& Cognition, 16, 421-435.

Schmidt, J., \& Besner, D. (2008). The Stroop effect: why proportion congruent has nothing to do with congruency and everything to do with contingency. Journal of Experimental Psychology: Learning, Memory, and Cognition, 34, 422-429.

Schmidt, J. R., \& De Houwer, J. (2012). Does temporal contiguity moderate contingency learning in a speeded performance task? The Quarterly Journal of Experimental Psychology, 65(3), 408-425.

Schmidt, J., De Houwer, J., \& Besner, D. (2010). Contingency learning and unlearning in the blink of an eye: a resource dependent process. Consciousness and Cognition, 19, 235-250.

Schnyer, D. M., Dobbins, I. G., Nicholls, L., Davis, S., Verfaellie, M., \& Schacter, D. L. (2007). Item to decision mapping in rapid response learning. Memory and Cognition, 35, 1472-1482.

Schnyer, D. M., Dobbins, I. G., Nicholls, L., Schacter, D. L., \& Verfaellie, M. (2006). Rapid response learning in amnesia: delineating associative learning components in repetition priming. Neuropsychologia, 44, 140-149.

Stoet, G., \& Hommel, B. (1999). Action planning and the temporal binding of response codes. Journal of Experimental Psychology: Human Perception and Performance, 25, 1625-1640.

Tukey, J. (1977). Exploratory data analysis. Reading, MA: AddisonWesley.
VanRullen, R. (2009). Binding hardwired vs. on-demand feature conjunctions. Visual Cognition, 17, 103-119.

Wagner, A. D., Maril, A., \& Schacter, D. L. (2000). Interactions between forms of memory: when priming hinders new episodic learning. Journal of Cognitive Neuroscience, 2, 52-60.

Waszak, F., Hommel, B., \& Allport, A. (2003). Task-switching and longterm priming: role of episodic stimulus-task bindings in task-shift costs. Cognitive Psychology, 46, 361-413.

Waszak, F., Hommel, B., \& Allport, A. (2004). Semantic generalization of stimulus-task bindings. Psychonomic Bulletin \& Review, 11, $1027-1033$.

Waszak, F., \& Pholulamdeth, V. (2009). Episodic S-R bindings and emotion: about the influence of positive and negative action effects on stimulus-response associations. Experimental Brain Research, 194, 489-494.

Waugh, N. C., \& Norman, D. A. (1965). Primary memory. Psychological Review, 72(2), 89-104.

Wendt, M., \& Kiesel, A. (2008). The impact of stimulus-specific practice and task instructions on response congruency effects between tasks. Psychological Research, 72(4), 425-432.

Wiggs, C. L., \& Martin, A. (1998). Properties and mechanisms of perceptual priming. Current Opinion in Neurobiology, 8, 227-233.

Wolfensteller, U., \& Ruge, H. (2011). On the timescale of stimulus-based action-effect learning. Quarterly Journal of Experimental Psychology, 64(7), 1273-1289. 